\title{
Populismo de esquerda versus populismo de direita no início do século XXI: o conflito político nos EUA, Inglaterra, França e Alemanha
}

Theófilo Machado Rodriguês

\begin{abstract}
Resumo
Com a publicação, em 2005, de $A$ razão populista, Ernesto Laclau trouxe o tema do populismo de volta para a agenda da teoria política. Mas o tema não ficou circunscrito somente aos debates teóricos. Nesse início de século assistimos ao crescimento de uma miríade de forças eleitorais que articulam a política sob o método do populismo. Essa forma de articulação de demandas e reivindicações ocorre tanto à direita quanto à esquerda do espectro ideológico. Tendo como suporte analítico o conceito de populismo de Laclau, o presente artigo investiga as recentes investidas eleitorais que atuam sob essa forma em quatro países: Estados Unidos, Inglaterra, França e Alemanha. A primeira seção é dedicada ao conceito de populismo em Laclau. A segunda seção observa o processo eleitoral estadunidense de 2016 com a pré-candidatura de Bernie Sanders e a vitória de Donald Trump. Na terceira parte é analisada a ascensão de Jeremy Corbyn no Partido Trabalhista britânico e de seu oposto, Nigel Farage, do UKIP. Na quarta, foram comparados os extremos que se apresentaram para a eleição presidencial francesa de 2017: Marine Le Pen, da Frente Nacional; e Jean-Luc Mélenchon, da antiga Front de Gauche, atual France Insoumise.Por fim, observa-se o crescimento do Die Linke e da AfD na Alemanha. A hipótese apresentada é a de que o conceito de populismo formulado por Ernesto Laclau e reafirmado por ChantalMouffe possui validade explicativa não apenas para países da América Latina, como já vem ressaltando uma parcela da literatura, mas também para os países do "norte".
\end{abstract}

\section{Palavras-chave}

Populismo. Ernesto Laclau.Teoriapolítica.

\begin{abstract}
With the publication in 2005 of On Populist Reason, Ernesto Laclau brought the populist subject back to the agenda of political theory. Yet the topic was not restricted to theoretical debates. In the beginning of this century, we have witnessed the growth of a myriad of electoral forces which articulate politics under the populist method. This kind of demands' articulation occurs on both the right and the left sides of the ideological spectrum. Based on the Laclau's concept of populism, the current article investigates the recent electoral campaigns in four countries: the United States, England, France and Germany. The first section is focused on the Laclau's concept of populism. The second section looks at the 2016 US election process with Bernie Sanders' pre-nomination and Donald Trump's victory. In the third part, the rise of Jeremy Corbyn in the British Labor Party and his oppositor, Nigel Farage, UKIP, is analyzed. In the fourth, the extremes that appeared in the 2017 French presidential election: Marine Le Pen, of the National Front; and Jean-Luc Mélenchon, from the former Front de Gauche, now France Insoumise, were compared. Finally, the growth of Die Linke and theAfD in Germany is observed. The hypothesis presented is that the concept of populism formulated by Ernesto Laclau and reaffirmed by Chantal Mouffe, has validity not only for Latin American countries, as the literature has already emphasized, but also for Northern countries.
\end{abstract}

\section{Keywords}

Populism. Ernesto Laclau.Political theory. 
Theófilo Machado Rodriguês

\section{Introdução}

Ao longo do século XX o conceito"populismo" na teoria social e política esteve mais comumente associado aos governos da América Latina. Nesse registro, experiências históricas como as de Perón na Argentina e as de Cárdenas no México são certamente as mais lembradas. Do ponto de vista teórico, as influências dos sociólogos argentinos Gino Germani(1973 e 2003) e TorcuatodiTella (1973) foram, sem margem de dúvidas, determinantes nessa direção. Também no Brasil, tanto o período pós-1930 de Getúlio Vargas, quanto a República de 46, foram analisados sociologicamente pela ótica do populismo. Em nossa literatura, sociólogos como Francisco Weffort (1980) e Octavio Ianni(1971, 1973 e 1975) foram alguns dos que trabalharam a interpretação da sociedade brasileira de 1930 a 1964 munidos desse conceito.

No início de século XXI, dessa vez acrescido da influência de uma outra matriz teórica oriunda de Ernesto Laclau, o "populismo" voltou a ser retomado como chave explicativa para a emergência de uma série de governos eleitos na América Latina com a participação de partidos à esquerda do espectro político. "Há um fantasma que assombra a América Latina, e esse fantasma é o populismo", disse Laclau em agosto de 2013 (LACLAU, 2013: p. 20).Chávez e Maduro na Venezuela, Lula e Dilma no Brasil, Morales na Bolívia, Fernando Lugo no Paraguai, Rafael Corrêa e Lenín Moreno no Equador, OllantaHumala no Peru e o casal Kirchner na Argentina foram algumas das experiências taxadas como populistas pelo debate na imprensa, ou mesmo por parcelas da literatura especializada. Se, de fato, esses governos mereceriam ser classificados como populistas é um debate ainda em aberto nas ciências sociais, como demonstram algumas recentes publicações sobre o tema (PERLATTO e CHAVES, 2016; MUDDE e KALTWASSER, 2017).

Mas o século XXI não trouxe consigo apenas a retomada das interpretações sociológicas sobre o populismo circunscritas geopoliticamente na América Latina; também ao norte, nas duas margens do Atlântico, ocorremensaios que analistas categorizam como populistas (MUDDE, 2007; JUDIS, 2016; MUDDE e KALTWASSER, 2017; SANTOS e MENDES, 2018). Nos Estados Unidos, na Inglaterra, na França e na Alemanha novas forças políticas de esquerda e de direita, a partir de narrativas identificadas com o populismo, emergiram nos últimos anos com certo sucesso eleitoral. Donald Trump e Bernie Sanders nos EUA, Nigel Farage e Jeremy Corbyn na Inglaterra,Marine Le Pen e Jean-Luc Mélenchon na França,Die Linke e AfD na Alemanhasão alguns dos exemplos mais expressivos. Como essas forças surgem em sociedades ditas modernas, até então vistas como inóspitas ao populismo, é um enigma que começa a ser decifrado pela análise sociológica. Essa é a contribuição interpretativa do presente artigo, que está subdividido em seis seções. Na primeira, está sintetizado de forma breve o conceito de populismo aqui adotado, oriundo de Ernesto Laclau e ChantalMouffe. As quatro partes seguintes apresentam alguns elementos do conflito político atual em EUA, Inglaterra, França e Alemanha. Por fim, há a apresentação de uma articulação e sistematização dos elementos que configuram esses populismos do norte.

\section{0 conceito de populismo em Ernesto Laclau e ChantalMouffe}

Em 2005 o argentino Ernesto Laclau publicou em Londres A razão populista, livro que chegou ao Brasil em 2013. Nele, Laclau propôs uma ressignificação do conceito de populismo que logrou certo sucesso e passou a ser adotado a partir de então de forma exponencial, tanto por analistas quanto por atores políticos.O populismo em Laclau não pode ser observado sob uma chave positiva ou negativa, mas sim como um método de construção do político; não se trata de um conteúdo específico ou de um tipo de ideologia, mas de uma forma complexa de articulação de demandas em determinada formação social. O populismo pressupõe a construção retórica de uma noção de "povo" que se opõe a um determinado inimigo. Aqui, a ideia de "nós" versus "eles", em que o "nós" é o "povo" é fundamental. Esse "nós" versus "eles" pode ser o proletariado contra a burguesia, os nacionais contra os imigrantes, os brancos contra os judeus, os progressistas contra os misóginos, racistas e homofóbicos etc.Mas como se forma esse "nós", como se forma o sentido de "povo"? Laclau observa que em determinados momentos da história algumas demandas sociais não são atendidas pelo establishment, pelo sistema político. Embora diferentes, essas demandas possuem uma lógica de equivalência: o fato de não serem atendidas pelas instituições. Essa lógica da equivalência articula as demandas umas às outras em torno da ideia de "povo". Contudo, para que possa se portar de modo consolidado é preciso que essas demandas encontrem uma 
representação simbólica que as sintetize, aquilo que Laclau chamou de um "significante vazio". Esse "significante vazio", no populismo, é, em geral, o nome do líder carismático. Como o populismo não possui um conteúdo específico, pode ser considerado de esquerda ou de direita em cada formação social e histórica onde ocorre. No caso latino americano do início do século XXI esse populismo, de acordo com Laclau, foi claramente mais identificado com a esquerda do espectro ideológico. Segundo o autor, na América Latina "o populismo está ligado à ascensão de regimes de esquerda e se fundamenta na construção de uma ordem nacional e popular que rompa com os ditames do Consenso de Washington" (LACLAU, 2013: p. 21). Já na Europa Ocidental o populismo do século XXI tem se baseado na xenofobia e no repúdio aos imigrantes, salientou Laclau na introdução à edição brasileira. Ou seja, pouco importa o conteúdo, do ponto de vista analítico, o relevante é a observação de como se dá a articulação daquilo que $o$ autor chama de corte populista.

De qualquer maneira, seja de esquerda, seja de direita, decisivamente o populismo se constitui sempre em torno de um corte. Em certo momento, o sistema institucional vigente entra em obsolescência e mostra sua incapacidade de absorver as novas demandas sociais pelas vias tradicionais; em decorrência disso, tais demandas tendem a se aglutinar fora do sistema, num ponto de ruptura com o sistema. É o corte populista (LACLAU, 2013: p. 21).

Como Laclau faleceu em 2014, não teve a oportunidade de observar de forma mais sistemática o crescimento do populismo de esquerda na Europa Ocidental e nos Estados Unidos. De certo modo, quem assumiu essa tarefa foi sua parceira intelectual e esposa, a cientista política belga ChantalMouffe. Entusiasta das novas forças de esquerda que emergem na Europa ocidental e nos EUA, Mouffe vem concedendo nos últimos anos diversas entrevistas onde as enquadra analiticamente como "populismos de esquerda". Do ponto de vista conceitual,fica claro como Laclau identifica, em $A$ razão populista, o populismo como uma forma de construção da política, despido, portanto, de qualquer conteúdo ${ }^{1}$. Mas isso não quer dizer que Laclau não tenha sua aposta ou preferência normativa pelo "populismo de esquerda". Pelo menos desde 1985, quando publicou com MouffeHegemonia e estratégia socialista, os dois autores advogam em favor de um projeto político que chamaram de "democracia radical". "Defendemos que as lutas contra o sexismo, o racismo, a discriminação sexual e em defesa do meio ambiente, precisam ser articuladas às dos trabalhadores num novo projeto hegemônico de esquerda", sintetizaram os autores (LACLAU e MOUFFE, 2015: p. 47). Essa agenda é certamente semelhante àquela das forças políticas que Mouffe define como populista de esquerda. Para Mouffe, "o desenvolvimento de um populismo de esquerda é o único caminho de luta contra o sucesso crescente do populismo de direita"2.

Como se percebe, não há em Laclau e Mouffe uma ontologia privilegiada do proletariado como há no marxismo ortodoxo: o sujeito que conforma o "povo" pode ser construído a qualquer momento pela união de diferentes demandas, podendo ou não a classe ser uma delas. Não que os dois sejam alheios às demandas de classe. Suas origens no marxismo não estão completamente apagadas em suas obras de maturidade. Apenas não consideram que a classe ocupe lugar privilegiado na construção da política; trata-se de somente uma demanda a mais dentre tantas outras possíveis. Daí suas obras serem conhecidas como pós-marxistas (LACLAU e MOUFFE, 2015: p. 36).

Há aqui uma clara aproximação entre Mouffe e Laclau e aquela agenda proposta por Nancy Fraser no início da década de 90. Fraser (1995) defende a tese de que políticas de redistribuição, ou seja, as demandas da classe trabalhadora, devem estar conectadas com as políticas de reconhecimento, aquelas da agenda identitária contra o racismo, o machismo, o sexismo etc. Em tempos mais recentes, Fraser passou a propor essa necessária articulação entre redistribuição e reconhecimento a partir de um discurso populista de esquerda, tal qual Mouffe e Laclau.

Para mim, 'populismo' não é uma palavra negativa. Jan-Werner Müller publicou um livro em 2016 dizendo que o populismo é inerentemente antidemocrático, excludente, persecutório, etc. Eu não concordo com isso, acho que é uma má definição do termo. Eu me sinto muito mais próxima de alguém como Ernesto Laclau, que viu o populismo como uma lógica que poderia ser articulada de muitas maneiras diferentes. É verdade 
que existem populismos reacionários, mas nem sempre é o caso. (...) Eu acho que há uma chance de ganhar e convencer mais pessoas agora usando uma retórica populista, mas, claro, tem que ser um populismo de esquerda ${ }^{3}$.

Em síntese, do ponto de vista analítico, como lógica articulatória o populismo não tem conteúdo, ele pode ser de esquerda ou de direita, de acordo com a forma como a ideia de "povo" é construída. Sob o olhar normativo, Laclau, Mouffe e Fraser concordam em apostar em um populismo de esquerda como resposta ao populismo de direita. Vejamos como esse embate vem ocorrendo nos últimos anos em quatro países: Estados Unidos, Inglaterra, França e Alemanha.

\section{0 caso americano: Trump x Sanders}

"O populista Trump chega à Casa Branca agitando a bandeira do nacionalismo", disse o El Pais ${ }^{4}$. "Trump se fecha no mundo do nacional-populismo", afirmou o editorial de 0 Globo5. "Trump leva o populismo de direita à Casa Branca", foi o título de um artigo da Revista Época ${ }^{6}$. Já o editorial do Estadão sobre a eleição de Trump alertou: "A volta do populismo" . Há praticamente uma unanimidade na interpretação da grande imprensa de que Donald Trump adotou o discurso populista como forma de alcançar a vitória na eleição presidencial dos Estados Unidos em 2016. Mas o que poucos atentam é para o fato de que, por muito pouco, seu adversário nessa eleição não foi um outro candidato também identificado como populista, Bernie Sanders.

Quando as primárias partidárias tiveram início em fevereiro de 2016, poucos acreditavam que outsiders como Donald Trump, no Partido Republicano, e Bernie Sanders, no Partido Democrata, poderiam realmente ser oficializados como candidatos presidenciais cinco meses depois. Mas o resultado eleitoral no primeiro estado a realizar as prévias, Iowa, em 02 de fevereiro de 2016, demonstrou que não seria fácil a vida do establishment partidário. Enquanto no Partido Republicano o senador Ted Cruz obteve $28 \%$ dos votos contra 24\% de Trump, no Partido Democrata a ex-secretária de Estado, Hillary Clinton, e o senador por Vermont, Bernie Sanders, empataram com $49 \%$ cada um. Ao longo dos cinco meses seguintes Trump ultrapassou Cruz e foi coroado candidato presidencial pelo Partido Republicano, enquanto Sanders ficou um pouco atrás de Clinton, mas com um protagonismo que o permitiu trazer importantes pautas para o Partido Democrata.

Com 75 anos de idade, Sanders é senador pelo estado de Vermont. Autointitulado "socialista democrático" e com um histórico de político independente, filiou-se ao Partido Democrata somente em 2015 para disputar as prévias do partido na corrida presidencial. Perfil diferente do bilionário empresário e apresentador de televisão, Donald Trump, que já esteve filiado tanto no Partido Republicano quanto no Democrata. Dono de hotéis e cassinos, Trump já foi inclusive o dono do concurso de beleza Miss USA. Com perfis tão distintos, o que os caracteriza sob essa mesma forma política definida como populismo? O fato de que tanto Sanders quanto Trump terem construído seus discursos contra o establishment político estadunidense.

O populismo, como já vimos, não constitui um conteúdo específico. O que lhe define é a forma como articula o "povo" contra uma determinada "elite". "A pergunta de amanhã é: quem vocês querem que governe a América, a classe política corrupta ou o povo?", bradou Trump na véspera da eleição8. Do outro lado, o alvo preferencial de Sanders sempre foi Wall Street e o mercado financeiro, que o senador caracterizava como a elite dos $1 \%$ que oprimia os trabalhadores dos $99 \%$. "Anunciamos formalmente ao establishment político e econômico deste país que o povo americano não continuará a aceitar uma economia viciada, na qual os americanos comuns trabalham mais horas para receber menos, enquanto quase todo o novo rendimento e riqueza vão para os $1 \%$ mais ricos", declarou Sanders em um discurso de campanha (MUDDE e KALTWASSER, 2017: p. 41-42). Povo versus elite, essa era a narrativa populista dos dois candidatos.

No caso de Trump, a construção do povo passava por trazer a velha classe trabalhadora do chamado "cinturão da ferrugem" de volta para a cena política. Por muitos anos essa região do "cinturão da ferrugem", que abrange estadoscomo Ohio, Michigan, Wisconsin, Illinois e Indiana foi um polo de produção industrial no país, com uma forte organização sindical. A globalização, os tratados de livre comércio - como o NAFTA - e o neoliberalismo levaram à desindustrialização da região, o que atingiu em cheio esses trabalhadores, que perderam seus empregos ou viram seus salários baixarem. A narrativa protecionista e anti-imigração surgiu como um oásis 
discursivo para esses trabalhadores que votaram em massa em Trump. Esse era o povo de Trump e seus inimigos eram os imigrantes - latinos em geral e mexicanos em particular - e a elite financeira dos grandes centros urbanos que estaria pouco interessada na manutenção dos empregos no país.

O populismo americano, claro, não nasceu após a crise de 2008. Em fins do século XIX, a expressão política do populismo já buscava seu espaço como terceiro partido na disputa eleitoral estadunidense. Candidato presidencial pelo Partido Populista, James B. Weaver alcançou em 1892 cerca de $9 \%$ dos votos, um número considerável em um sistema bipartidário (GARCIA JURADO, 2010). Naquele momento o populismo "referia-se a um movimento de agricultores de esquerda" (MICHAEL, 2016). Ao longo do século XX, outros dois candidatos populistas buscaram um terceiro partido para a disputa presidencial: em 1968, George Wallace obteve 13,5\% dos votos pelo American IndependentParty; já o bilionário texano Ross Perot obteve 18,9\% em 1992, como independente, e em 1996, pelo Partido Reformista, 8,4\% dos votos. Todos eles buscando os votos da heartland, a América profunda, contra a "a Costa Leste corrupta" (MUDDE e KALTWASSER, 2017: p. 39). Com efeito, até o fim do século XX o único que logrou sucesso em articular um discurso populista em uma campanha presidencial foi 0 ator Ronald Reagan, presidente entre 1981 e 1989. Após a profunda crise econômica de 2008 o populismo americano reorganizou-se paralelamente em dois movimentos sociais polarizados no espectro político ideológico: o Occupy Wall Street e o TeaParty. Ambos preocupados em criticar a ajuda pública oferecida pelos governos de Bush e Obama ao capital financeiro que entrou em declínio pós-2008. Mas, com suas respectivas nuances.

O TeaParty surgiu no início de 2009 como resposta ao plano de resgate econômico aos bancos que fora proposto em 2008. Tratava-se, inicialmente, de uma série de protestos locais contra a política econômica nacional, mas que, posteriormente, incorporou outras agendas, como o combate à proposta de reforma do sistema de saúde feita por Obama. E sua influência é crescente. De acordo com Michael (2016), "o TeaParty é um movimento que congrega mais de dois mil grupos locais e nacionais". A partir de uma sondagem CNN//New York Times, Botelho (2010) constatou que "os teapartierssão majoritariamente brancos (89 por cento), do sexo masculino, casados e têm mais de 45 anos". Curioso notar que, não obstante esse perfil social de "homens, brancos, velhos", uma de suas principais lideranças é a ex-governadora do Alasca Sarah Palin. Com apoio do TeaParty, Palin foi a candidata a vice-presidência da república na chapa do Partido Republicano em 2008. Destacam-se, ainda, na liderança do TeaParty o ex-congressista pelo Texas, Ron Paul, e seu filho, Rand Paul, senador pelo Kentucky, ambos republicanos. Por tudo isso, embora seja um movimento social, o TeaPartyé também considerado por muitos como a ala extrema-direita do Partido Republicano. Em outras palavras, o que o TeaPartyorganizou foi um populismo de direita renovado para o século XXI.

Com um perfil social e ideológico oposto ao do TeaParty, o Occupy Wall Streetteve início em 17 de setembro de 2011, no Zuccotti Park, em Manhattan. "Nós somos os 99\%", era a palavra de ordem dos milhares de jovens que participavam daquele movimento 9 . Tratava-se, portanto, da articulação de um "povo", os 99\%, contra aquela elite representada pelo 1\%. Mudde e Kaltwasser (2017: p. 41) sustentam que "o Occupy conjugou uma agenda de justiça social progressista com populismo". Ou seja, um populismo de esquerda. De acordo com Chomsky (2013, p. 117), o Occupy trazia "uma clara preocupação e um claro compromisso com questões de desigualdade, o poder extraordinário das instituições financeiras, o papel das finanças e do dinheiro em geral na compra e na formatação das eleições". Outro observador e até mesmo participante dos protestos do Occupy foi o filósofo SlavojZizek, para quem:

O movimento Occupy Wall Street implica duas ideias básicas: (1) o descontentamento com o capitalismo enquanto sistema (o problema é o sistema capitalista como tal, não sua corrupção particular); (2) a percepção de que a forma institucionalizada da democracia representativa multipartidária não é suficiente para combater os excessos capitalistas, isto é, a democracia precisa ser reinventada. (...) (ZIZEK, 2012, p. 92).

Por caminhos opostos, os dois movimentos populistas nascidos pós-2008 conseguiram, em 2016, levar suas agendas das ruas para as instituições políticas através da disputa presidencial daquele ano. Grande parte das lideranças do TeaParty apoiou Donald Trump no Partido Republicano, ao passo que os jovens do Occupy Wall Street identificaram no pré-candidato à vaga do Partido Democrata, Bernie Sanders, um altivo porta voz. A linha 
de continuidade que seguia do populismo de direita do TeaParty até a narrativa eleitoral de Trump era nítida. A construção do povo americano em oposição a dois inimigos bem particulares: no âmbito político, o establishment governante, incluídos os próprios dirigentes do Partido Republicano; no âmbito social, os imigrantes mexicanos e muçulmanos que supostamente tiravam o emprego dos americanos nativos - por óbvio, no discurso de Trump os nativos não são os indígenas, mas sim os brancos. "Donald Trump dá voz a muitos americanos que se sentem abandonados por Washington, Wall Street e os grandes meios de comunicação social", sustenta Michael (2016). Seu slogan, "tornar a América grande novamente", produz ao menos duas imagens nos eleitores: "no plano externo, uma América respeitada, influente e razoavelmente temida, impondo um tipo de ordem e segurança estável no mundo; no plano interno, uma América próspera, de pleno emprego e salários altos, onde a mobilidade social não é uma miragem, mas uma realidade palpável" (BOTELHO, 2016).

A mesma linha de continuidade era encontrada no populismo de esquerda. Um dos elementos dessa continuidade do Occupyfoi "a divisão populista dos $99 \%$ versus $1 \%$ na retórica do senador democrata e candidato presidencial Bernie Sanders" (MUDDE e KALTWASSER, 2017: p. 41). Sanders não explorou o sentimento nacionalista contra determinadas etnias, como fez Trump: sua potência mobilizadora foi direcionada contra Wall Street, o locus privilegiado do capital financeiro na América. George Michael define do seguinte modo as diferenças entre esses dois populismos:

Os populistas de esquerda da atualidade, tais como os manifestantes do Occupy Wall Street, procuram um governo que crie uma rede de segurança, redistribua a riqueza de forma mais igualitária e contenha o poder das grandes empresas. Em contraste, a versão de direita do populismo atual, do qual o TeaPartyé o principal exemplo, vê o governo como o problema e não como a solução (MICHAEL, 2016).

Apesar de ter sido derrotado por Hillary Clinton nas prévias presidenciais do Partido Democrata em 2016, o populismo de esquerda de Sanders conseguiu influenciar o início de uma reorganização interna no partido. A derrota de Clinton para Trump na eleição presidencial fez o establishment democrata perder muito de sua força junto aos seus eleitores, o que abre a porta para a militância mobilizada por Sanders ocupar mais espaços institucionais no partido. A vitória de Trump também exige uma reorganização do establishment do Partido Republicano. Como nos mostra Michael (2016), "o sucesso eleitoral de Donald Trump ilustra a insatisfação aguda que muitos conservadores americanos têm com a ala tradicional do Partido Republicano".

Populismo precisa ser combatido com populismo, diria ChantalMouffe. Na medida em que era cada vez mais certo ao longo de 2016 que Trump seria o candidato do Partido Republicano, a partir da articulação de um populismo de direita, Mouffe acredita que o Partido Democrata deveria ter optado pela narrativa de um populismo de esquerda, que estava presente em Sanders.

I see Sanders as an example of a left-populist movement and Trump as a rightpopulist. It is really a pity that Sanders did not get the nomination. He would have had a much better chance against Trump and would have brought together many more people through pure enthusiasm for an alternative and change ${ }^{10}$.

Não foi o que ocorreu e Trump sagrou-se vitorioso. Mas a nova vaga do populismo norte americano está apenas em seu começo e ainda é possível que o Partido Democrata saiba reorganizar-se para enfrentar Trump nos próximos anos.

\section{0 caso britânico: Nigel Farage $x$ Jeremy Corbyn}

Assim como nos Estados Unidos, a sensação de mal-estar com a política, onde todos os partidos pareciam ser iguais, também ocupou certo espaço no senso comum inglês. O establishment reproduziu por muito tempo uma ordem neoliberal, antidemocrática, que começa a ser questionada pela maioria da população (JONES, 2015). Porta voz desseestablishment, o ex-primeiro ministro Tony Blair, em artigo para o The New York Times, questionou preocupado: "Como isso aconteceu? (...) Movimentos insurgentes de esquerda e direita, apresentando-se como porta-vozes de uma revolta popular contra o establishment político, podem se alastrar 
rapidamente ${ }^{m 11}$. Esse é o pano de fundo para a emergência de um duplo populismo inglês, à direita com Nigel Farage e à esquerda com Jeremy Corbyn.

Identificado com um populismo de direita, o Partido de Independência do Reino Unido, UKIP na sigla em inglês, surgiu em 1993. Seu principal sucesso eleitoral tem sido nas eleições para o Parlamento Europeu, onde, em 2014, foi o partido mais votado, tendo obtido 24 das 73 cadeiras em disputa. O mesmo não ocorreu nas eleições parlamentares de 2015: apesar de ter sido o terceiro partido mais votado, conquistou apenas uma cadeira naquele ano. Entre 2010 e 2016 a liderança do partido esteve com Nigel Farage, considerado por muitos um exemplo de líder populista. Nessa direção, Mudde e Kaltwasser (2017: p. 51) sugerem que Farage busca "apresentar-se como o 'homem comum' britânico, em sintonia com as ideias e os interesses do 'povo'"'. 0 populismo do UKIP nos últimos anos baseou-se na articulação do nacionalismo britânico contra a União Europeia. Essa defesa consolidou-se com a vitória do Brexit $^{2}$ no referendo realizado em 23 de junho de 2016 . Mas a articulação desse discurso não se resume à crítica à União Europeia. Junto com ela vem a leitura de que os imigrantes são inimigos a serem combatidos a partir de uma legislação nacional mais forte. De acordo com Farage,

O que nós queremos fazer é mudar a nossa relação com a União Europeia, retomar o controlo das nossas fronteiras e pôr em prática uma política positiva de imigração, que o povo da Grã-Bretanha vai esmagadoramente apoiar, e com isso quero dizer que queremos um sistema de pontos como os australianos para decidir quem vem para viver, trabalhar e estabelecer-se neste país ${ }^{13}$.

A base social desse populismo de direita é bem semelhante àquela que foi articulada por Trump nos EUA. Na espirituosa expressão de John Judis (2016: p. 134), o UKIP organizou a "revolta dos deixados para trás". Esses eleitores do UKIP são, em sua maioria, habitantes de pequenas cidades que no passado viviam da mineração e da indústria. Entretanto, após o governo de Margaret Thatcher, essas velhas cidades industriais tornaram-se fantasmas e esses eleitores, que tradicionalmente votavam com os trabalhistas, sentiram-se "deixados para trás". Essa classe trabalhadora que antes votava no Partido Trabalhista transferiu suas preferências políticas para 0 UKIP. E o partido, através de Farage, soube criar uma narrativa coerente com essa experiência de vida dos "deixados para trás": o discurso de que a culpa desses imigrantes tirarem empregos dos trabalhadores ingleses era de dupla dimensão: no campo exterior, a responsabilidade era da União Europeia; internamente, o inimigo era a elite financeira de Londres. A solução para esse imbróglio era o Brexit (JUDIS, 2016: p. 135-137).

Se o UKIP foi o partido protagonista na mobilização pró-Brexit, Farage foi seu principal porta voz. De acordo com Judis (2016: p. 138, tradução nossa), "Farage conduziu a campanha do referendo num clássico estilo populista, colocando o povo contra o establishment". A ponto de, logo após a vitória, anunciar publicamente que não continuaria como líder do partido, pois sua missão já teria sido cumprida: "Nunca fui um político nem quis fazer da política a minha profissão. Estive na política com o objetivo de tirar o Reino Unido da União Europeia", declarou em Londres ${ }^{14}$. Discurso conveniente para quem quer apresentar-se distante da política tradicional. Curiosamente, o sucesso da campanha do UKIP pelo Brexit não refletiu em uma vitória eleitoral nas eleições parlamentares de 2017: o partido não conseguiu eleger nenhum deputado para o parlamento inglês.

A trajetória do populismo de esquerda no país foi, grosso modo, inversa em relação ao populismo de direita. Assim como nos EUA, o populismo de esquerda emergiu no seio de um partido tradicional, no caso, do Partido Trabalhista Britânico. Mas, diferente do caso americano, esse populismo foi vitorioso internamente. Em 12 de setembro de 2015 o veterano parlamentar Jeremy Corbyn, com 66 anos de idade, assumiu a liderança do LabourParty. Conhecido por sua agenda anti-austeridade, anti-guerras e em defesa do meio ambiente, Corbyn iniciou um processo de aggiornamento programático no partido. Por óbvio, a iniciativa entrou em conflito com a burocracia partidária e com a maioria da bancada parlamentar do Labour. O impasse exigiu que em 2016 os filiados fossem chamados novamente a escolher quem deveria ser o líder do partido. E mais uma vez Corbyn foi eleito, com mais de $60 \%$ dos votos. Ao contrário do que propunha a burocracia partidária, a base social dos trabalhistas queria ver a agenda política de Corbyn representando o partido. Corbyn não construiu um discurso contra a União Europeia, como fez o UKIP. Mas, como o populismo de direita, buscou articular sua base social em 
torno daquela mesma classe trabalhadora abandonada pelas políticas neoliberais. Sua fronteira agonística delimitava-se com a burguesia financeira de Londres, tal qual Sanders fez contra o 1\% nos EUA. De certo modo, é irônico imaginar como esses dois senhores - homens, heterossexuais e brancos - obtiveram tanto sucesso em mobilizar a juventude e suas pautas como a luta-antirracista, antissexista e antibelicista para dentro da política. Para os dois, a construção do "povo" pressupunha a livre e ativa participação de jovens, negros, mulheres e homossexuais na política. Algo não tão claro no discurso de seus opositores de direita. Aliás, sobre as semelhanças entre essas duas campanhas é sintomática a anedota contada por Corbyn em entrevista para Naomi Klein:

Bernie me ligou no dia seguinte à eleição. Eu estava meio dormindo, assistindo a alguma coisa na TV. E Bernie me ligou para dizer: "Parabéns pela campanha. Fiquei interessado nas suas ideias. De onde você as tirou?" E eu disse: "Então, foi de você, na verdade $^{\prime 15}$.

Em síntese, na Inglaterra, o populismo de direita foi vitorioso em sua agenda pelo Brexit, mas não obteve sucesso em conquistar cadeiras parlamentares. O populismo de esquerda, pelo contrário, perdeu em relação ao Brexit, todavia, pode se considerar vitorioso em sua ocupação institucional no parlamento e no interior do Partido Trabalhista. Sob qualquer ângulo que se busque, a gramática populista consolidou-se de fato no país.

\section{0 caso francês: Le Pen x Mélenchon}

O populismo de direita francês é, certamente, um dos mais consolidados na Europa ocidental. Seu principal instrumento partidário é a Frente Nacional fundada em 1972 por Jean-Marie Le Pen e hoje dirigida por sua filha, Marine. Assim como Trump nos EUA e Farage na Inglaterra, Le Pen articula a classe trabalhadora que sofreu com a globalização e as políticas neoliberais de austeridade. Ao sofrimento dessa classe trabalhadora Le Pen articula um vocabulário xenofóbico que responsabiliza a União Europeia e os imigrantes pelo declínio francês. Conforme Chantal Mouffenosexplica:

In France, the majority of the working class is voting for Marine Le Pen. It's easy to understand, because these sectors have become the losers in globalization. Le Pen has been able to articulate-in a xenophobic vocabulary-the demands of the popular classes. They are democratic demands. They are ordinary people who are suffering. But Le Pen comes with the discourse: "I understand that you are suffering. The people who are responsible are the immigrants." She is establishing a frontier against immigrants ${ }^{16}$.

A força eleitoral da Frente Nacional é crescente e há algum tempo o partido é o terceiro maior na França. Em 2002, Jean-Marie Le Pen conseguiu chegar ao segundo turno da eleição presidencial francesa, mas foi derrotado por Jacques Chirac com uma avassaladora diferença de $82 \%$ a $18 \%$. Na eleição seguinte, em 2007, houve um declínio momentâneo e Jean-Marie ficou em quarto lugar com 10,4\% dos votos. O crescimento da Frente Nacional voltou com Marine como candidata em 2007, quando alcançou a terceira posição com 18\%. Finalmente, em 2017 a façanha de 2002 repetiu-se, dessa vez com Marine conquistando 34\% dos votos no segundo turno, mas foi derrotada pelo liberal Emmanuel Macron com $66 \%$.

Segundo Mudde e Kaltwasser, a Frente Nacional é um paradigma de partido populista de extrema-direita. "Le Pen transformou a extrema-direita desorganizada e elitista francesa num partido populista radical de direita bem organizado, que inspirou partidos e políticos de toda Europa (2017: p. 50-51). Embora as semelhanças entre os discursos de Marine e Jean Marie sejam muitas, a filha busca afastar-se do extremismo do pai. Esse rompimento culminou com a expulsão do próprio fundador do partido em 2015. Marine busca ampliar sua fatia no eleitorado e para isso as declarações do pai em favor do período nazista não contribuíam. Jean-Marie gostava de repetir, por exemplo, que as câmaras de gás eram mero detalhe na história da Segunda Guerra Mundial, algo que Marine discorda. $\mathrm{O}$ combate à entrada dos muçulmanos em França também é feito de forma mais cuidadosa pela 
Theófilo Machado Rodriguês

filha, bem como a admiração que Jean-Marie mantinha pelo Regime de Vichy ${ }^{17}$ tem sido minimizada no seio da Frente Nacional (JUDIS, 2016: p. 144-145).

Ao mesmo tempo em que o populismo de direita francês pode ser considerado uma força estável, o populismo de esquerda busca seu espaço. Esse processo teve início em 2008, após o rompimento do senador Jean-Luc Mélenchon com o Partido Socialista. Crítico da moderação programática do PS, Mélenchon organizou um novo partido e uma nova frente política: o Parti de Gauche e a Front de Gauche. Pela Front de Gauche - coalizão formada pelo Parti de Gauche e pelo Partido Comunista Francês - disputou a eleição presidencial de 2012 e conquistou $11 \%$ dos votos, a quarta posição naquele pleito. Em 2016, Mélenchon reorganizou o seu movimento: substituiu a Front de Gauche pela France Insoumise. E o apoio para sua campanha cresceu na eleição de 2017. Mélenchon obteve $19,6 \%$ dos votos, menos de 2 pontos percentuais atrás de Marine Le Pen e da possibilidade de disputar o segundo turno. Pierre Laurent, secretário-geral do PCF, exprimiu bem o que significou o resultado para a esquerda francesa:

Pela primeira vez desde há décadas, milhões de cidadãos e cidadãs que aspiram à transformação social quase conseguiram alçar seu candidato Jean-Luc Mélenchon ao segundo turno. No momento em que nos exprimimos e tendo em vista os primeiros resultados à nossa disposição, nós Ihes dizemos que os quase $20 \%$ de votos obtidos por Jean-Luc Mélenchon levantam uma nova esperança para o futuro, para reinventar a nova esquerda que o nosso país espera para destravar o sistema político e a democracia ${ }^{18}$.

A narrativa de Mélenchon passa pela articulação dos mais diversos segmentos subalternos da sociedade francesa em defesa de um novo pacto social, que seria consolidado por uma assembleia constituinte capaz de dar início à VI República no país. Sua agenda é voltada para os trabalhadores e sua principal proposta é a redução da jornada semanal de trabalho de 35 para 30 horas. Esse discurso lhe permite falar diretamente com a classe trabalhadora, sem a intermediação sindical, ainda que uma grande parte dos sindicatos o apoie, via PCF. Mas o programa de Mélenchon vai para além da questão econômica, da redistribuição. A incorporação de pautas dos novos movimentos sociais é clara, como o respeito às identidades e a defesa de políticas de reconhecimento.

No caso francês, a ascensão dos dois tipos de populismo é proporcional ao declínio dos dois principais partidos do establishment francês, o Partido Socialista e os Republicanos. Na última eleição de 2017, nenhum desses dois partidos que se revezaram no poder nos últimos 40 anos chegou ao segundo turno. Sintomático da reorganização pela qual passa o sistema partidário no país.

\section{0 caso alemão: Die Linke x AfD}

A entrada no Bundestag da Alternativa para a Alemanha, partido de extrema direita, após a eleição de 2017, alertou o mundo para a perigosa ascensão desse tipo de movimento. Partidos de extrema direita já conquistaram espaços em outros países anteriormente, mas a história da Alemanha com o nazismo, que chegou ao poder pelo voto na década de 30, certamente criou um mal-estar generalizado. Esse cenário não é um raio em dia de céu azul, expressão que os filósofos alemães tanto gostam, mas algo que vem sendo construído há algum tempo. Tanto a caminhada do Partido Conservador, CDU, da primeira-ministra Angela Merkel para o centro, quanto o mesmo movimento realizado pelo Partido Social Democrata, SPD, da esquerda para o centro, criou um clima de insatisfação com o sistema político alemão. Os dois principais partidos, que deveriam representar programas opostos, tornaram-se muito semelhantes, e até mesmo consolidaram uma coalizão de governo ${ }^{19}$. Se a alternativa eleitoral não estava nem na centro-esquerda, nem na centro-direita, os extremos encontraram um vácuo a ser preenchido.

O populismo de esquerda percebeu primeiro esse vazio. O Die Linke, partido que sucedeu o velho Partido Comunista que governou a antiga Alemanha Oriental, foi criado em 2005 para disputar aquela eleição. E seu início foi de sucesso, tendo conquistado a terceira posição no Bundestag, com 54 cadeiras. A partir da captura de parcela do eleitorado que pertencia ao SPD, o Die Linke cresceu na eleição seguinte, em 2009, e passou a ter 76 cadeiras. No entanto, foi ultrapassado pelo Partido Liberal que conquistou a terceira maior bancada no 
parlamento. Curiosamente, em 2013, apesar de ver sua bancada reduzir para 64 parlamentares, voltou a ser a terceira maior atrás apenas do SPD e da CDU/CSU. Em 2017 cresceu novamente, agora para 69 parlamentares, mas tanto o Partido Liberal quanto a recém-criada Alternativa para a Alemanha ultrapassaram o Die Linke, colocando-o como quinta maior bancada. É fato que o partido consolidou sua posição na vida política alemã. Pela esquerda, é o único capaz de oferecer uma agenda alternativa. Conforme assinala IngarSolty, "na luta contra o pensamento único neoliberal, Die Linke é o único ocupante de um campo aberto" (2008, p. 31, tradução nossa). Mas isso não significa que seja hoje uma alternativa real ao governo de Angela Merkel.

O populismo de direita alemão é um pouco mais novo, surgiu em 2013 com a fundação da Alternativa para a Alemanha, AfD. Mas sua estreia foi decepcionante, já que não conseguiu ultrapassar a cláusula de barreira de $5 \%$ dos votos imposta pelo sistema eleitoral alemão e, assim, ficou de fora do Bundestag. Isso, entretanto, não impediu que o movimento crescesse e se tornasse a terceira maior força do país na eleição de 2017. Não obstante ser um partido cada vez mais popular, em particular nas regiões da antiga Alemanha Oriental, o perfil dos fundadores do partido é circunscrito a uma determinada elite: são professores universitários de economia e de direito e líderes empresariais alemães insatisfeitos com a União Europeia.

A AfD constantemente enfrenta problemas internos de direção. O primeiro deles se deu com a saída do fundador do partido, o economista Bernd Lucke, em 2015. Após perder a liderança do partido para a radical Frauke Petry, Lucke desfiliou-se e fundou a Aliança pelo Progresso e Ressurgimento, ALFA, um partido mais distante do populismo, liberal na economia e nos costumes. O rosto mais nítido do populismo de direita alemão é o da empresária e lider do partido Frauke Petry. Mais radical que Lucke, Petry o substitui como líder do partido em julho de 2015. Petry é rigorosa crítica da entrada de muçulmanos no país, autointitulada conservadora nacionalista. Em seu radicalismo, chegou mesmo a declarar que a polícia deveria utilizar armas de fogo para impedir a entrada de refugiados ilegais no país: "Nenhum agente policial quer disparar contra um refugiado e eu também não. Mas como último recurso, devem poder utilizar armas de fogo", defendeu Petry em $2016^{20}$. Petry permaneceu como líder do partido até abril de 2017, quando renunciou ao cargo e foi substuituída pelo conservador Alexander Gauland e por Alice Weidel, atuais líderes do partido no Bundestag desde a vitória eleitoral. Weidel critica o apoio da Alemanha para a Grécia, despreza a política de refugiados de Merkel e, mesmo assim, é considerada a mais moderada na direção partidária, ou, a "voz da razão", como apresentada pela imprensa21. Há nessa leitura uma certa contradição. Curiosamente, logo após a vitoriosa eleição de setembro de 2017, Petry anunciou que assumiria sua cadeira no Bundestag como independente e que sairia da AfD junto com seu marido, o também dirigente partidário Marcus Pretzell, por não concordar com o radicalismo adotado pela legenda ${ }^{22}$. Ou seja, em uma reviravolta, Petry apresentou-se como mais moderada que a "voz da razão" de Weidel.

Paralelo ao crescimento do populismo de direita nas instituições políticas, está o seu avanço na sociedade civil. Em 2014, um movimento social de extrema-direita que começou no Facebook, ocupou as ruas de Dresden, na Saxônia, para se oporà imigração de muçulmanos na Alemanha. Trata-se do PEGIDA, Europeus Patriotas contra a Islamização do Ocidente, movimento fundado por Lutz Bachmann. Esse movimento conseguiu levar alguns milhares de pessoas para as ruas contra a entrada dos refugiados no país mas, ao mesmo tempo, gerou um mal-estar na sociedade alemã, que logo se mobilizou para ocupar as ruas em repúdio ao PEGIDA. O líder Bachmann é uma pessoa polêmica. Em 2015, uma foto sua fantasiado de Hitler circulou pelas redes sociais, o que o levou a ser investigado pela justiça do país ${ }^{23}$. Apesar do extremismo, sua influência na sociedade alemã é crescente. Pesquisa realizada pela tradicional revista alemã, Der Sipegel, confirmou que 34\% dos alemãs concordam com a afirmação do PEGIDA de que a influência do islã alastra-se pela Alemanha ${ }^{24}$.

Entre o movimento social e o partido político há uma nítida tensão. Em maio de 2016, a liderança nacional do partido, sob o comando de Petry, decidiu que os membros da AfD não deveriam participar dos eventos da PEGIDA. A decisão não foi unânime, já que muitos militantes da AfD são de extrema-direita e concordam com a agenda da PEGIDA. Com a saída de Petry pode ser que essa decisão seja revista, já que o novo líder partidário, Alexander Gauland, não é um severo crítico do movimento. Embora a agenda seja semelhante, o combate à imigração, a AfD não quer ser identificada com a simbologia radical, até mesmo nazi-fascista, que marca o PEGIDA. Seja como for, as duas forças políticas nasceram ao mesmo tempo, filhos de uma mobilização que reivnindica uma mesmoa agenda. Representam as duas faces, uma social e outra política, do recente populismo de direita alemão. 
Theófilo Machado Rodriguês

\section{Considerações finais}

A hipótese de que o conceito de populismo proposto por Laclau e reafirmado por Mouffe tem validade explicativa não apenas para a América Latina, mas também para os países do "norte" parece se confirmar nesse breve roteiro percorrido por países como Estados Unidos, Inglaterra, França e Alemanha. Esses países foram selecionados por apresentarem de forma mais clara a oposição entre dois tipos de populismo: um de direita e outro de esquerda. Contudo, o populismo do "norte" vai para além desses casos: Áustria, Itália, Grécia e Espanha são apenas mais alguns exemplos dessa Europa Ocidental onde o populismo faz-se presente nesse início do século XXI (MUDDE e KALTWASSER, 2017). Intuitivo imaginar que a validade explicativa dessa gramática sociológica para os países do "norte" talvez altere a forma preconceituosa como uma parcela da literatura especializada trata o suposto atraso dos países do sul. No fim das contas, o populismo está tão presente aqui quanto alhures. É sempre bom lembrar que as primeiras experiências históricas do populismo surgiram justamente no "norte", nos Estados Unidos e na Rússia do século XIX (GARCIA JURADO, 2010). Na primeira metade do século XX esse populismo ressurgiu na Europa Ocidental: Alemanha e Itália são casos exemplares. O populismo da América Latina do século XX é, portanto, uma experiência tardia.

Seria muito forte afirmar que o populismo veio para ficar. Assim como emergiu em diversas partes do mundo ocidental nos últimos anos, pode entrar em declínio em um futuro próximo. Não se sabe. $O$ fato é que hoje, seja de esquerda, seja de direita, o populismo é uma dinâmica de construção política que não pode ser ignorada pela literatura especializada. Entre 2016 e 2017 o populismo de direita elegeu um presidente nos Estados Unidos, foi ao segundo turno da eleição presidencial francesa, aprovou o Brexit na Inglaterra e conquistou a terceira posição no Bundestag alemão. O populismo de esquerda não obteve o mesmo sucesso, mas não deve ser subestimado. Nos Estados Unidos mobilizou uma enorme militância para a disputa interna do Partido Democrata, na Inglaterra elegeu o líder do Partido Trabalhista e na Alemanha e França constitui a quarta maior força política.

Há, claro, quem considere tudo a mesma coisa. Provocada pelo jornal Le Figaro a comentar a eleição francesa, ChantalMouffe delimitou essa diferença entre os dois tipos de populismo:

A diferença fundamental entre o populismo de esquerda e o populismo de direita é como o povo é construído. A população é uma categoria sociológica. Ao contrário, o povo é uma categoria construída, uma categoria política. A maneira pela qual Le Pen construiu um povo é muito diferente da forma como Jean-Luc Mélenchon construiu um povo ${ }^{25}$.

O populismo, tal qual formulado por Laclau, é uma forma de articular e construir a política, sem um conteúdo determinado. Por essa razão pode ser de esquerda ou de direita. Conforme foi demonstrado ao longo do artigo, quando a articulação dessa política organiza o nacionalismo e identifica como fronteira agonística os imigrantes, ou algum tipo de preconceito étnico, identitário ou racial esse populismo é considerado de direita. Nos Estados Unidos esse preconceito é direcionado contra negros e mexicanos; na Europa, contra muçulmanos. Por outro lado, quando o "povo" é organizado contra uma determinada elite econômica que impulsiona programas neoliberais de austeridade fiscal, seja o centro financeiro de Londres, seja Wall Street, esse populismo é definido como de esquerda. Em outra entrevista, dessa vez para o The European, Mouffe sintetizou exatamente essa diferença entre os dois populismos. E acrescentou: para combater o populismo de direita é necessário um populismo de esquerda.

Quando eles [populismo de direita] falam sobre o 'povo', referem-se a uma entidade que está restrita a uma certa categoria de povo na qual os imigrantes estão excluídos. Isso é normalmente acompanhado por um discurso xenofóbico, que é muito negativo para a democracia. Mas não devemos esquecer a possibilidade de um populismo de esquerda no qual a noção de 'povo' é construída de uma forma diferente: ela inclui tanto imigrantes quanto todo o povo trabalhador de um país específico. Os adversários do povo nesse caso não são os imigrantes, mas as grandes corporações transnacionais e todas as forças da globalização neoliberal. Para mim, o desenvolvimento de um 
Theófilo Machado Rodriguês

populismo de esquerda é o único caminho de luta contra o crescente sucesso do populismo de direita ${ }^{26}$.

O populismo pode construir esse povo de diversas formas. Na leitura do populismo de direita, há um forte aspecto nacional contra a globalização e a imigração. Para Trump, o pilar do "povo" americano são os trabalhadores do "cinturão da ferrugem" que perderam seus empregos para a globalização e, supostamente, para os mexicanos; para Le Pen e Farage, o "povo" é formado pelos trabalhadores do interior da França e da Inglaterra, que responsabilizam os muçulmanos e a União Europeia por suas dificuldades; para a AfD, os alemães que foram "deixados para trás" na Alemanha Oriental e que perderam seus empregos para refugiados ilegais. 0 populismo de esquerda é mais inclusivo. Não há fronteira antagonística com os imigrantes, pelo contrário, eles fazem parte do "povo". O inimigo a ser enfrentado é o 1\%, a elite econômica e financeira de Paris, Londres, Berlim ou Wall Street. Ademais, a agenda do populismo é ainda mais inclusiva. De forma ativa e positiva, para além da redistribuição, ou seja, da pauta econômica, a agenda do reconhecimento, das políticas de identidade, do protagonismo do negro, da mulher, do LGBT, é exaltada. O populismo de esquerda traduz o que Laclau e Mouffe definiram como "democracia radical" e o que Nancy Fraser articulou como "redistribuição e reconhecimento".

O conflito se dá entre o populismo de esquerda e o populismo de direita. Mas não significa que os partidos liberais ou conservadores do centro político estejam derrotados. Na Inglaterra e na Alemanha, os partidos conservadores de Theresa May e Angela Merkel permanecem no poder. Na França, Emmanuel Macron demonstrou sua força ao ser eleito presidente na última eleição com um claro discurso de "terceira via", tal qual aquele formulado por Anthony Giddens (2001) e implementado por Bill Clinton e Tony Blair na década de 90. Também nos Estados Unidos essa "terceira via" - que Nancy Fraser, em artigo recente, apelidou de "neoliberalismo progressista"27 - sobrevive, ainda que em fase terminal, com Hillary Clinton. Aliás, em seu já mencionado artigo para o The New York Times, o próprio Tony Blair conclamou o centro político a dar a volta por cima na Inglaterra: "A direita ataca imigrantes, enquanto a esquerda investe contra banqueiros. (...) O centro precisa retomar sua tração política, redescobrir sua capacidade de analisar os problemas e encontrar soluções que superem o ódio populista"28. Se conseguirá, somente o tempo dirá. De fato, os sinais são de que o zeitgeistseja populista.

(Recebido para publicação em dezembro de 2017)

(Reapresentado em maio de 2018)

(Aprovado para publicação em junho de 2018)

\section{Cite este artigo}

RODRIGUÊS, Theófilo Machado. Populismo de Esquerda versus Populismo de Direito no Início do Século XXI: o Conflito Político nos EUA, Inglaterra, França e Alemanha.Revista Estudos Políticos: a publicação semestral do Laboratório de Estudos Hum(e)anos (UFF). Rio de Janeiro, Vol. 9 |N.1, pp.70 -85, julho de 2018. Disponível em:http://revistaestudospoliticos.com/

\section{Notas}

1. Apenas do ponto de vista conceitual, do ponto de vista da lógica da articulação política, que entendemos o populismo como "despido de conteúdo". Quando essa lógica articulatória se realiza em determinada formação social, o populismo passa a ter um conteúdo, pode ser de esquerda ou de direita, por exemplo. 
2. The European, 15.01.2014. Tradução nossa. Disponível em: $<$ http://en.theeuropean.eu/chantal-mouffe--3/7859-fighting-right-wingpopulism-in-europe>.

3. Opera Mundi, 19.09.2017. Disponível em:

<http://operamundi.uol.com.br/conteudo/geral/48014/nancy+fraser+tod o+movimento+emancipador+atual+precisa+adquirir+uma+dimensao+p opular+.shtml>.

4. El Pais, 20.01.2017. Disponível em: <http://brasil.elpais.com/brasil/2017/01/20/internacional/1484928539_92 4950.html>.

5. O Globo, 21.20.2016. Disponível em:

<http://oglobo.globo.com/opiniao/trump-se-fecha-no-mundo-donacional-populismo-20327242>.

6. Revista Época, 09.11.2016. Disponível em: $<$ http://epoca.globo.com/sociedade/ruth-deaquino/noticia/2016/11/trump-leva-o-populismo-de-direita-casabranca.html>.

7. Estadão, 11.11.2016. Disponível em:

<http://opiniao.estadao.com.br/noticias/geral,a-volta-dopopulismo,10000087697>.

8. El Pais, 16.11.2016. Disponível em: <https://brasil.elpais.com/brasil/2016/11/14/internacional/1479150607_2 82338.html>.

9. Referência à desigualdade nos EUA entre os $1 \%$ mais rico e o restante da população.

10. The Nation, 15.12.2016. Disponívelem:

$<$ https://www.thenation.com/article/america-in-populist-times-aninterview-with-chantal-mouffe/>.

11. The New York Times. 24.06.2016. Disponível em:

<https://www.nytimes.com/2016/06/26/opinion/tony-blair-brexitsstunning-coup.html>.

12. Expressão inglesa para a saída do Reino Unido da União Europeia.

13. Euronews, 05.03.2015. Disponível em:

<http://pt.euronews.com/2015/03/05/ukip-quer-acabar-com-imigracaoem-massa>.

14. El Pais, 04.07.2016. Disponível em:

<https://brasil.elpais.com/brasil/2016/07/04/internacional/1467624309_9 73638.html>.

15. The Intercept, 18.07.2017. Entrevista: Naomi Klein e Jeremy Corbyn debatem o mundo que queremos. Disponível em:

$<$ https://theintercept.com/2017/07/18/video-naomi-klein-e-jeremycorbyn-debatem-o-mundo-que-queremos/>.

16. The Nation, 15.12.2016. Disponível em:

$<$ https://www.thenation.com/article/america-in-populist-times-aninterview-with-chantal-mouffe/>.

17. Regime de Vichy é como tornou-se conhecido o período da história francesa de 1940 até 1944 quando o governo do país esteve sob influência nazista. 
18. Portal Resistência, 23.04.2017. Disponível em:

$<$ http://www.resistencia.cc/pcf-destaca-bom-resultado-de-melenchon-eapela-a-derrotar-marine-le-pen-no-segundo-turno/>.

19. Em 2013, CDU/CSU e SPD firmaram um acordo de governança e formaram o terceiro governo de "Grande Coligação", ou seja, um governo formado pelos dois principais partidos do país.

20. DN, 06.02.2016. Disponível em:

<https://www.dn.pt/mundo/interior/frauke-petry-do-odio-ao-euro-paraos-tiros-contra-os-refugiados-5017695.html>.

21. DW, 24.09.2017. Disponível em: <http://www.dw.com/pt-002/aliceweidel-e-afd-a-extrema-direita-no-parlamento-alem\%C3\%A3o/a40645165>.

22. Público, 26.09.2017. Disponível em: <https://www.publico.pt/2017/09/26/mundo/noticia/frauke-petryabandona-a-alternativa-para-a-alemanha-1786788> .

23. Reuters, 21.01.2015. Disponível em:

<http://www.reuters.com/article/germany-islam-pegida/german-pegidaleader-investigated-after-hitler-pose-idUSL6N0V02VI20150121>.

24. Der Spiegel, 21.12.2014. Disponível em: <http://www.spiegel.de/international/germany/anti-muslim-pegidamovement-rattles-germany-a-1009245.html>.

25. Le Figaro, 11.04.2017. Tradução nossa. Disponível em: <http://www.lefigaro.fr/vox/politique/2017/04/11/3100120170411ARTFIG00090-entretien-exclusif-avec-chantal-mouffe-laphilosophe-qui-inspire-melenchon.php $>$.

26. The European, 15.01.2014. Tradução nossa. Disponível em: $<$ http://en.theeuropean.eu/chantal-mouffe--3/7859-fighting-right-wingpopulism-in-europe>.

27. Dissent, 02.01.2017. Disponível em:

$<$ https://www.dissentmagazine.org/online_articles/progressiveneoliberalism-reactionary-populism-nancy-fraser $>$.

28. The New York Times, 24.06.2016. Traduçãonossa.Disponível em: <https://www.nytimes.com/2016/06/26/opinion/tony-blair-brexitsstunning-coup.htmlhttps://www.nytimes.com/2016/06/26/opinion/tonyblair-brexits-stunning-coup.html>.

\section{Bibliografia}

BOTELHO, Teresa. O novo populismo conservador do movimento TeaParty e as intercalares americanas. Relações Internacionais, Lisboa, n. 27, p. 105-114, set. 2010.

. A implosão anunciada do Partido Republicano:

Populismo americano em tempo de incerteza. Relações Internacionais, Lisboa, n. 51, p. 43-56, set. 2016.

CHOMSKY, Noam. Sistemas de poder: conversas sobre as revoltas democráticas globais e os novos desafios ao império americano. Rio de Janeiro: Apicuri, 2013.

FRASER, Nancy. From Redistribution to Recognition?Dilemmas of Justice in a 'Post-Socialist' Age, New Left Review, I/212, JulyAugust, 1995. 
GARCIA JURADO, Roberto. Lasraícesdel populismo. Los movimientos populistas delsiglo XIX enRusia y Estados Unidos. Argumentos (Méx.), México, v. 23, n. 63, p. 267-288, agosto 2010. DI TELLA, Torcuato. Populismo y reformismo. In: GERMANI, Gino; DI TELLA, Torcuato; IANNI, Octavio. Populismo y contradicciones de claseenLatinoamérica. Mexico: Ediciones Era, 1973.

GERMANI, Gino. Democracia representativa y clases populares. In: GERMANI, Gino; DI TELLA, Torcuato; IANNI, Octavio. Populismo y contradicciones de claseenLatinoamérica. Mexico: Ediciones Era, 1973. Autoritarismo, fascismo y populismo nacional. Buenos Aires: UniversidaddiTella, 2003.

GIDDENS, Anthony. A terceira via: reflexões sobre o impasse político atual e o futuro da social-democracia. Rio de Janeiro: Record, 2001.

IANNI, Octavio. O Colapso do Populismo no Brasil. 2. ed. Rio de Janeiro: Civilização Brasileira, 1971.

. Populismo y relaciones de clase. In: GERMANI, Gino; DI TELLA, Torcuato; IANNI, Octavio. Populismo y contradicciones de claseenLatinoamérica. Mexico: Ediciones Era, 1973.

. A formação do Estado Populista na América

Latina. Rio de Janeiro: CivilizaçãoBrasileira, 1975.

JONES, Owen. The establishment: and how they get away with it. London: Penguin, 2015.

JUDIS, John. The populist explosion: how the great recession transformed american and european politics. New York: Columbia Global Reports, 2016.

LACLAU, Ernesto. A razão populista. São Paulo: Três estrelas, 2013. ; MOUFFE, Chantal. Hegemonia e estratégia socialista. São Paulo: Intermeios, 2015.

MICHAEL, George. A nova onda populista nos Estados Unidos. Relações Internacionais, Lisboa, n. 50, p. 23-38, jun. 2016. MUDDE, Cas. Populist Radical Right Parties in Europe. Cambridge/New York: Cambridge University Press, 2007. ; KALTWASSER, Cristóbal Rovira. Populismo: uma brevíssima introdução. Lisboa: Gradiva, 2017. PERLATTO, Fernando; CHAVES, Daniel. Repensar os populismos na América do Sul: debates, tradições e releituras. Macapá: Unifap, 2016.

SANTOS, Boaventura de Sousa; MENDES, José Manuel. Demodiversidade: imaginar novas possibilidades democráticas. Belo Horizonte: Autêntica, 2018.

SOLTY, Ingar. The Historic Significance of the New German Left Party.Socialismanddemocracy, p, 1-34, Junho, 2008.

WEFFORT, Francisco. O populismo na política brasileira. Rio de Janeiro: Paz e Terra, 1980. 
Theófilo Machado Rodriguês

ZIZEK, Slavoj. O ano em que sonhamos perigosamente. São Paulo: Boitempo, 2012. 